\title{
Corrigendum
}

\section{Corrigendum to "The Role of the Appendix Testis in Normal Testicular Descent: Is There a Connection?”}

\author{
Zlatan Zvizdic $\mathbb{D}^{1,2}$ Dragana Zivkovic, ${ }^{3}$ Jasmin Sabanovic, ${ }^{1,2}$ and Emir Milisic ${ }^{1}$ \\ ${ }^{1}$ Clinic of Pediatric Surgery, Clinical Center University of Sarajevo, Sarajevo, Bosnia and Herzegovina \\ ${ }^{2}$ Medical Faculty, University of Sarajevo, Sarajevo, Bosnia and Herzegovina \\ ${ }^{3}$ Institute for Child and Youth Health Care of Vojvodina, Faculty of Medicine, University of Novi Sad, Novi Sad, Serbia \\ Correspondence should be addressed to Zlatan Zvizdic; zlatan.zvizdic@gmail.com
}

Received 26 March 2019; Accepted 27 March 2019; Published 14 April 2019

Copyright (C) 2019 Zlatan Zvizdic et al. This is an open access article distributed under the Creative Commons Attribution License, which permits unrestricted use, distribution, and reproduction in any medium, provided the original work is properly cited.

In the article titled "The Role of the Appendix Testis in Normal Testicular Descent: Is There a Connection?" [1], the affiliation of the second author was incorrect. The corrected affiliations' list is shown above.

\section{References}

[1] Z. Zvizdic, D. Zivkovic, J. Sabanovic, and E. Milisic, "The role of the appendix testis in normal testicular descent: is there a connection?" BioMed Research International, vol. 2018, Article ID 3078031, 5 pages, 2018. 


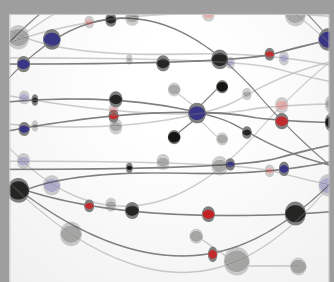

The Scientific World Journal
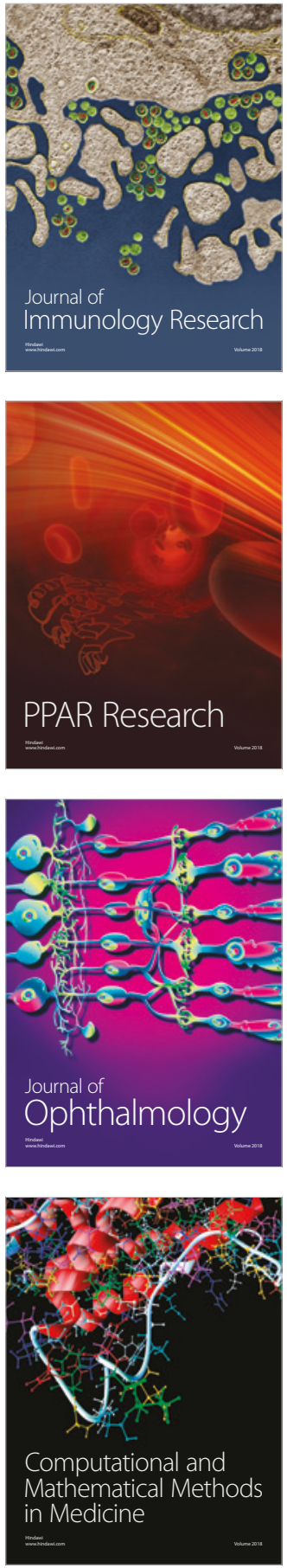

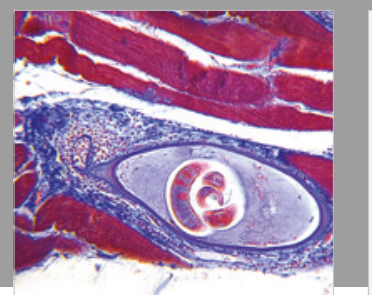

Gastroenterology Research and Practice

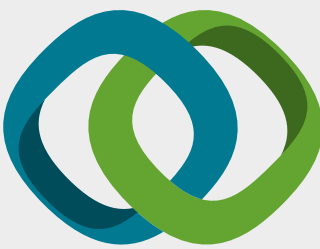

\section{Hindawi}

Submit your manuscripts at

www.hindawi.com
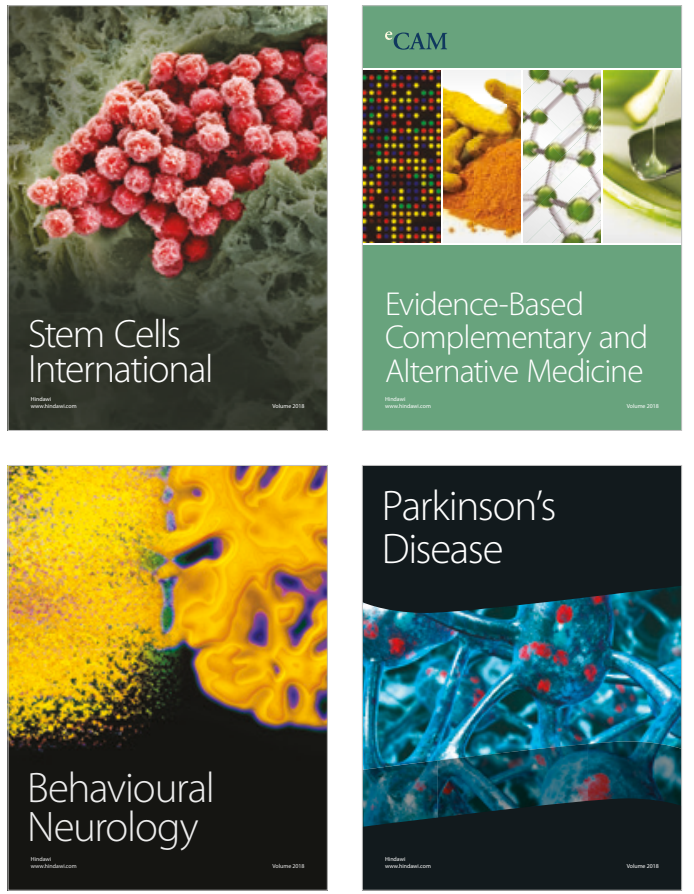

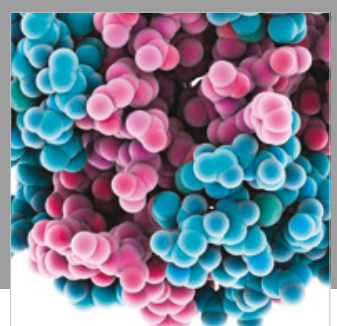

ournal of

Diabetes Research

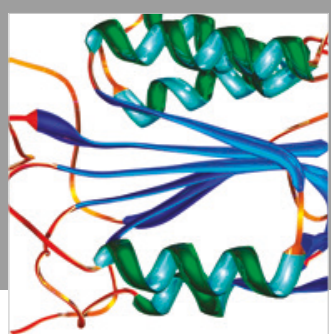

Disease Markers
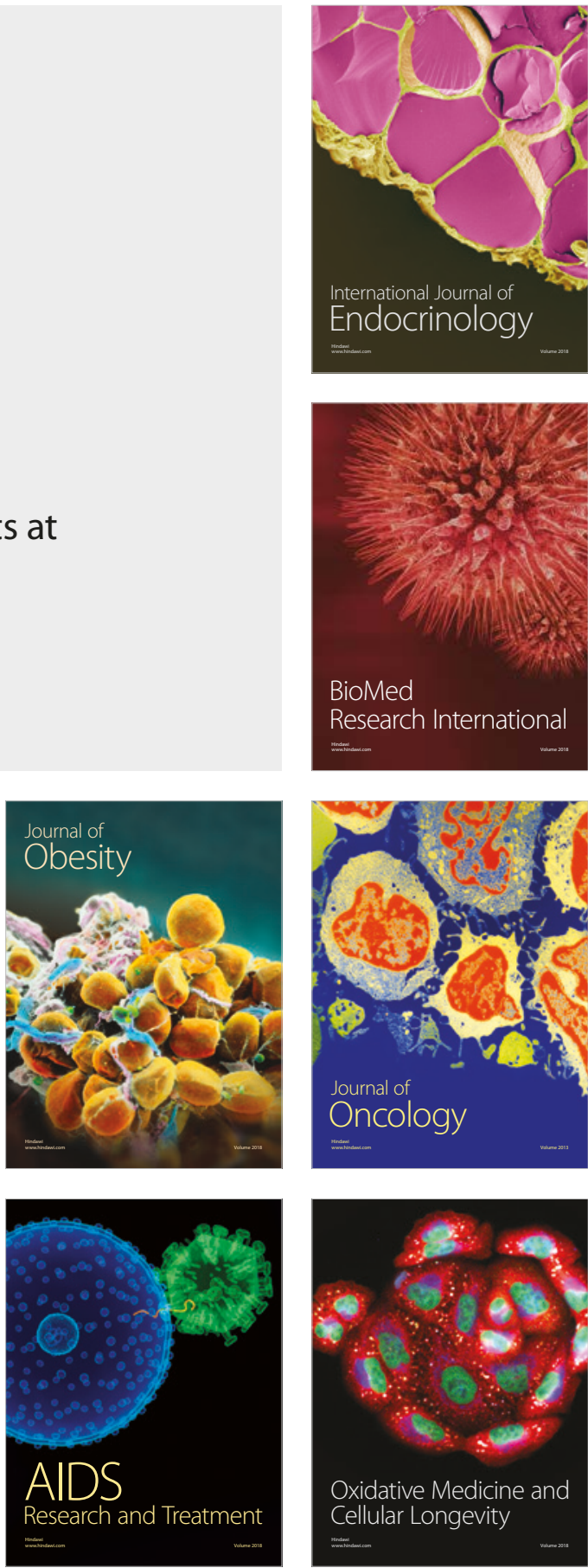